REGENERATION AND TRANSPLANTATION IN ANIMALS.

By Prof. E. Konschelt.

Reciexeratiox and transplantation are intimately connected, for transplantation is regularly followed by regenerative processes. The regeneration of lost part mer tale place in aduit individuals, long past the perod of development. It is a phenomenon common to the restes apt to renlace lost parts by a process of true regeneration thing brestitio other parts into service and
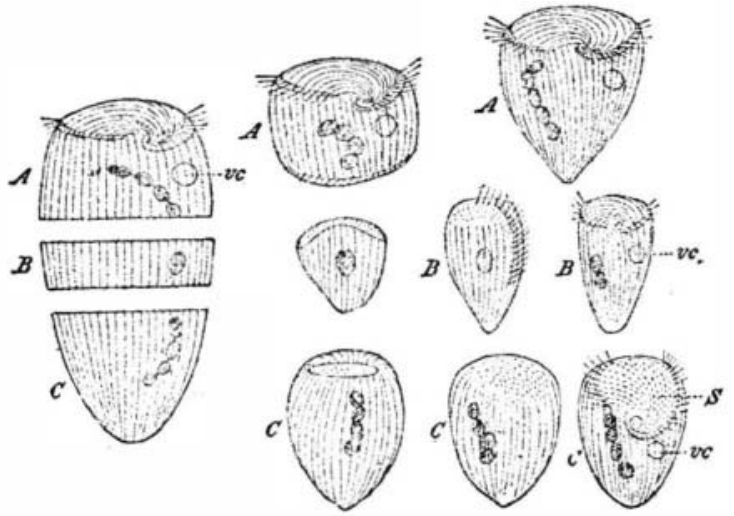

Fig. 1.-Regeneration of a Stentor Cut Into Three Pieces.

vc, Pulka ing vacuole ; S, peristom, or mouth region. (After A. Gruber.)

crystals has lately been hinted at, but the broken crystal grows at every point, not only at the surface of fracture.

In the eighteenth century Trembly, Réaumur, Bonnet, Spallanzani, and others proved that the powe of regeneration is common to many animals, including fresh water polyps, worms, echinodermata (sta fishes, sea urchins, etc.), and the larvæ of amphibia We now know that it occurs in all classes of animals, from unicellular organisms to vertebrates.

The regeneration of protozoa, the lowest unicellular animals, is of especial importance because it occurs in a simple cell, as it does in plants. If a stentor is cut transversely into two or more pieces each piece develops, according to its original position, a head, a tail, or both (Fig. 1, $A, B, C$ ). Regeneration has been observed in a fragment containing only $1 / 64$ th of the bulk of the animal. This reconstruction of an entire animal from so small a fragment is analogous to the development of larvæ from small fragments of eggs and the segmentation of the unicellular stage of sea urchins and other animals into 8,16 , or 32 cells. In the regeneration of protozoa as well as highe animals striking changes of form occur (Fig. 1), but in the former the nucleus is all essential. Fragment of a Stentor which contain no part of the nucleus be come rounded but die without undergoing true regeneration (Fig. 2). Similar phenomena are observed in plants.

In the cases described above regeneration was in duced by mutilation, but protozoa as well as metazoa (multicellular animals) are also capable of "physiological regeneration" caused by purely physiological factors. This includes the creation of reproductive organs, as needed, in protozoa, and the shedding and renewal of skin, hair, feathers, antlers, etc., in metazoa.

A striking power of regeneration after mutilation is exhibited by the fresh water polyp Hydra, of which small segments first become rounded, then elongated and finally develop heads and tails (Fig. 3).

The fresh water worms called Planaria possess a still greater power of regeneration, for longitudinal as well as transverse segments develop into complete animals (Fig. 4)

Such regenerative power as this is not common.

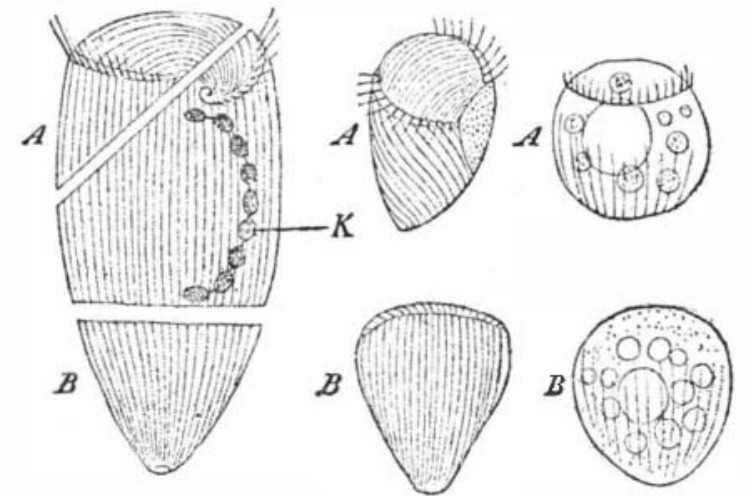

Fig. 2.-A Stentor of Which the Amputated Parts Do Not Regenerate Because They Contain None of the Nuc?eus.

$A, B$, Amputated parts; $K$, nucleve

Some of the ring worms (Oligochaetae) are, however still more remarkable, for they not only produce, with tolerable certainty, complete individuals from a dozen or more pieces, but they possess the faculty of autotomy or self-division, an external stimulus causing them to break into fragments, which may develop its a certain analogy to the ordinary forms of asexual its a certain

Even in strongly regenerative animals the faculty is in abeyance in certain parts of the body and in
general the power of regeneration diminishes as the organization becomes more complex. Yet it is re tained by many articulata, fishes, amphibia, and even reptiles, in such exposed parts as legs, fins, and tails. Hence Weismann regards regeneration as a phenom enon of adaptation to environment, but this view is not universally accepted.

In regeneration occurring in the healing of wound the origin of the new organs and tissue is of especial interest. The old theory that like is always produce from like and that the process is analogous to embryonal development has been disproved by the discovery of numerous exceptions. These include the formation of the ends of the intestinal canal in the regeneration of Annelida or ring worms, from the nner cotyledon and not, as in embryonal development from the outer one, the formation of the gill case from the abdominal sack in ascidians (sea-squirts); the formation of the foot from the cup in the feather-sta (Comatula); and the often-quoted formation of the ens from the iris in the eye of the triton.

In the last and many other cases regeneration from like parts is impossible as all such parts have bee removed. Yet the rezeneration takes place. Th same phenomenon has been observed in embryos in which certian organs developed, although the part rom which those organs are normally produced had been extirpated. When regeneration of this sort occurs in an adult animal it may be due to the persistence of special groups of cells in the embryonal stage or to a retrograde differentiation of all substance. There is much evidence to support the latter assump-

Barfurth has found that the regenerated part is usually placed normally to the cut surface. As the latter is often oblique to the axis of the body the new part must undergo a subsequent development if it is to remain permanently capable of functional life. In general, processes of growth and transformation play a great part in regeneration. This appears in
the development of thin, broad slices of Hydra and Planaria into long and slender individuals, and still more clearly in Morgan's experiments with Bipalium, Fig. 5 illustrates the transformation of a segment, $A$,

into a complete individual, $D$.
Here, as in the regeneration of long and thick term Here, as in the regeneration of long and thick term-
inal segments by earth worms (Fig. 6 ) there must be extensive adaptive changes and, probably, a retrogression or degradation which furnishes the required material. In ascidians, Driesch has observed retrogression carried to the point of complete fusion of the original structure, followed by regeneration from the amorphous mass.

The loss of a part of an organism may be followed not by regeneration of that part, but by a compensatory regulation or hypertrophy of another part, usually he corresponding part on the opposite side of the body. In the cases of regeneration which have been described (Figs. 1 to 5) it might almost be taken for granted that the anterior end of the fragment would develop a head and the posterior one a tail. This pol arity is still more marked in plants but even in them here are exceptions.

A willow tree planted in an inverted position develops roots from its buried apex and shoots from its unburied base and similar phenomena have been oberved in the alga Bryopsis.

Jacques Loeb has produced similar reversals of polarity in various hydroid polyps by planting piece of these plant-like animals in an inverted position,

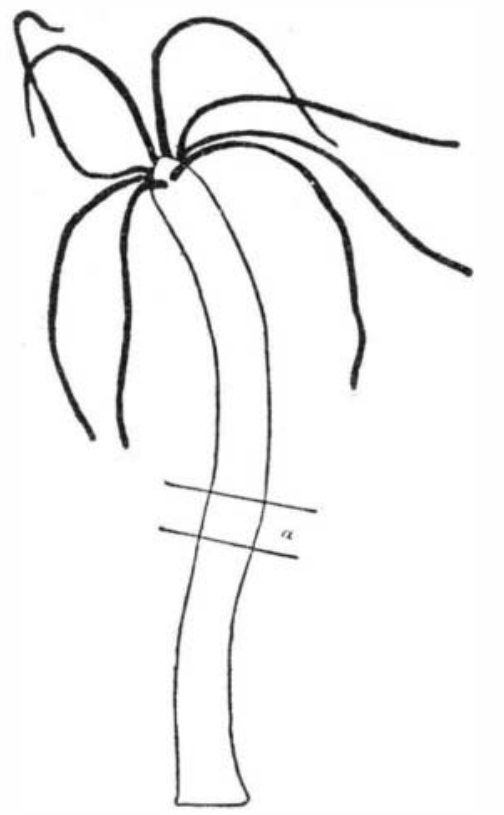

omorphosis have been produced by Herbst in crabs, in which a feeler sprouted in the place of an eye that had been removed together with the optic ganglion, but a new eye was developed if only the eye had bee removed and the ganglion left undisturbed (Fig. 9). The occurrence of heteromorphosis proves that in regeneration forms may be produced that cannot perform the normal functions of the lost parts because they are defective or superfluous. The duplication of
heads, tails, and limbs is analogous to the duplication of embryonal parts.

The cause of the occurrence and even of the char acter of regeneration has been sought in the nature of the mutilation. The normal condition of the system is disturbed and resistances of growth are removed

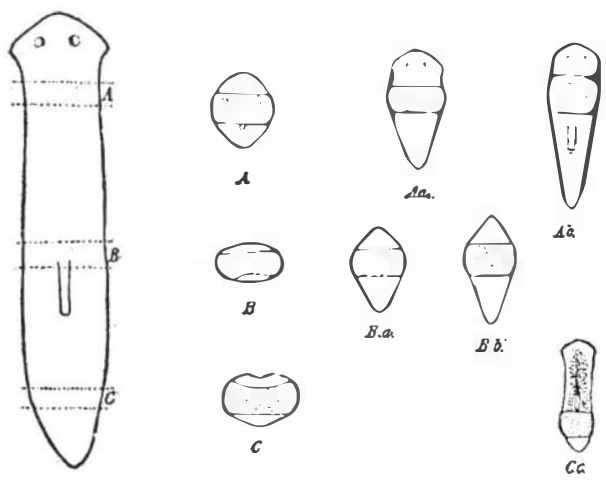

Fig. 4.-Planaria, of Which Small Transverse Slice

$(A, B, C)$ Develop Into Complete Worms.

so that changes of relative tension acquire import ance even in cases where the regeneration does not ake place precisely at the wound itself.

In many cases, such as the replacement of the eyes of decapod crustaceans (Fig. 9) the influence of the nervous system is plainly apparent. Other interna factors that affect regeneration are the state of nutrition, age, and chemotactic actions. The external fac tors include temperature, light, gravity, changes in the surrounding medium, etc.

Transplantation is closely related to regeneration because it necessarily causes wounds which give rise to regeneration, but independently of this, transplantation is frequently accomplished by extensive regenration.

Because of its importance in surgery human trans plantation has been practised for centuries and transplantations have long been made in the bodies of animals as well. Trembly's experiments on $H y d r a$ are of especial interest in this connection because of their striking contrast to transplantations in human surgery. In the latter the transplanted portions are ery small, but in the lower animals, portions which are large in comparison with the rest of the body even portions capable of independent existence, . can ing individuals. This has been done with $H_{y y d r a}$ ing individuals. This has been done with $H$,
worms, pupæ of insects, and larvæ of amphibia. worms, pupæ of insects, and larvæ of amphibia. the parts are taken from the same individual or inthe parts are taken from the same individual or in-
dividuals of the same species. It is very difficult to dividuals of the same species. It is very
com

The success and the permanence of the union are
and The success and the permanence of the union are
favored by the growing together of similar organs, which by the growing together of similar organs, hinel indivilual shows no trace of its methe comformation pieces have becn kept alive ten years and combined
Fig. 5.-Hydra. A Transverse Segment (a) Becomes Rounded $\left(a, a^{1}, a^{y}\right)$, Elongates $\left(a^{3}\right)$ Forms Tubercles $\left(a^{4}\right)$ and Develops Into a New Polyp $\left(a^{5}, a^{6}\right)$

hat both ends were freely exposed to the water ( Fig. ).

Loeb has given the name heteromorphosis to this growth of an organ or member in a part of the body in only in Coelenterata (jelly fishes, corals, snonges, etc.) and

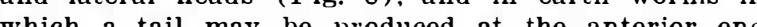
of a fragment. Very interesting phenomena of heter- amphibia larvæ have survived their metamorphosis into the adult stage.

Small fragments transplanted to other organs are seldom capable of permanent existence in their new environment. Sooner or later they perish from lack of nutriment or other causes. But sometimes they perform their functions after transplantation as in Ribbert's transplantations of the mammary gland of a guin 
Transplantations to other parts of the body are much more successfully accomplished in embryos an larvæ, and the subsequent development and trans formation of such transplanted portions have led to most interesting and astonishing results (Born, Harrion, Braus, Spemann, Banchi, Lewis)

The combination of parts taken from different species is of peculiar interest because of the importance of the question whether parts welded together exer any influence on each other. Such combinations, as we have seen, are very difficult to effect, but parts of
earth worms and larval amphibia of different species have been brought into long-continued and even permanent union. There is certainly no mutual influence, for even very small parts, which are, so to speak,
completely dominated and necessarily nourished by

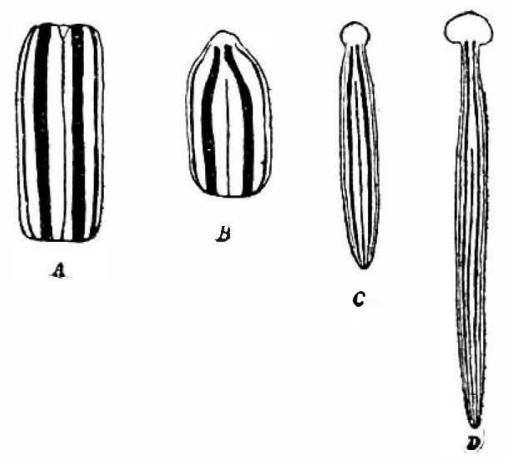

Fig. 5.-Tranoformation of a, Segment $(A)$ of Bipalium
Through the Forms $B$ and $C$ to the Perfect Animal, $D$. Through the Forms $B$ and $C^{\prime}$ to the
(After Morgan.)

their far larger partners, always preserve the characters peculiar to their species and transmit them to the parts which they create by regeneration. In like manner fragments transplanted to other parts of the body of the same individual do not change in char acter, unless they fail to make organic connection with their new environment and are therefore treated as foreign bodies by the organism.

Another interesting question concerns the effect of the orientation of the transplanted part upon the success of the transplantation and union. In Hydra it is possible to overcome the normal polarity and effect permanent union of two parts joined.by like poles, a result which agrees with the phenomena of heteromorphosis observed in these simple organisms, but oest and Bornhave proved that earth worms an amphibia larvæ can also be joined by like poles. Thi proves that polarity is much weaker in animals tha in plants, in which inverted grafts never flourish.

From animal combinations connected by like poles a part of one component has been partly amputated with the result that the stump generated a tail in place of an amputated head, or the reverse. If these cases are not simply heteromorphosis they indicate an influence of the larger upon the smaller component in respect to polarity which is inconsistent with the usual preservation of characteristics by transplanted parts. In any event, these observations point to new and important relation between transplantatio and regeneration.-Translated for the Scientific American from Umschau.

\section{ELECTRICITY IN THE TREATMENT OF}

By John V. Shoеmaker.

IN order to obtain the best results in practice it is important that we shall bear in mind the limitation of electricity in clinical medicine, because if these ar disregarded we may expect to meet with certain disappointment. Extravagant claims made by too enthusiastic advocates are not only unjust to this valuable therapeutic resource, but they are also unjust to the patients who are led to expect impossibilities.

I think it will lead to a clearer view of electricit from the medical standpoint if we lay aside for the moment any preconception we have in our mind with regard to its being a mysterious, life-givin orce, capable of working miracles upon the human body, and as being at all times constructive, energizing, and beneficent in its effects in pathological con-
ditions. This, I know, is the popular idea, which has

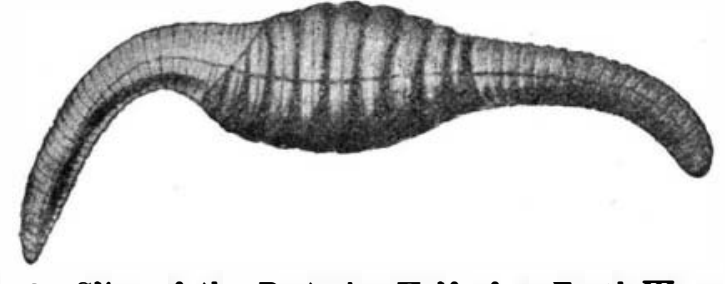

Fig. 6.-Slice of the Posterior Half of an Earth Worm (Helodulus longus) with Regenerated Head and Tail.

been largely founded upon the seductive and boastfu advertisements of charlatans, who have found this a fruitful field in which to work on the credulity of the ignorant public. "There is no sacred disease," said Hippocrates, "or all diseases are equally sacred."
So we may say with regard to remedies, there is no So we may say with regard to remedies, there is no
mysterious remedy, or all remedies are equally mys terious.

Mercury, arsenic and other potent drugs may, according to circumstances, act as caustic agents and destroy tissues, or they may act as tonics and favo

*Abatract of a paper read before the Penusglvania state Medical
Society at Bedfo d Springa, $P_{a}$. physiological changes. In the same way electricity may be used in medicine to destroy tissue, or, on the ther hand, to favorably influence metabolism, depending upon the form in which it is used and the skill with which it is applied.

Let us now briefly consider the forms in which electricity is utilized in medical practice. We ob-

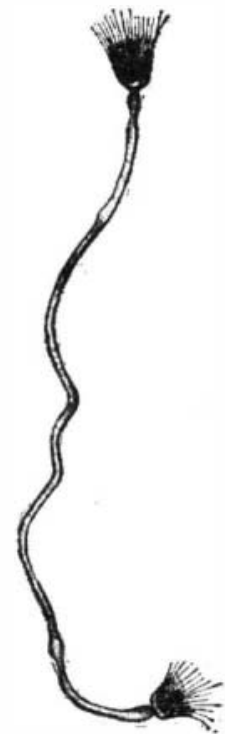

Fig. 7.-Piece of Communal Stem of Fubularia mesem at Both Ende. (After Jacques Loeb.)
ath with New Heads or Polyps Gro

serve, in the first place, that it is used both indirectly and directly. Among the indirect applications of electricity are those in which it is employed as a source of heat, light, magnetism, and X-rays. As illustration of the former I may mention the galvanocautery, the electric light and the Roentgen apparatus; also the
electromagnet. Illustrations of the direct application electromagnet. Illustrations of the direct application
are the galvanic, the static, and the induced currents, are the galvanic, the static, and the induced currents,
obtained from the ordinary medical coil or from the obtained from the ordinary medical coil or from the
large commercial dynamo. The latter, however, is large commercial dynamo. The latter, however, is purposes, but it may be reduced by transformers and
controllers, or "stepped down" so that it can be used therapeutically, as well as for heating and lighting the therapeutically

The first point that $I$ wish to make is that electricity is always the same in itself, but, like the other agents I have named, it may be given in different dosage and in different ways, so that entirely different therapeutic results may be obtained. Success in therapeutics, whether in the use of electricity or any other remedial agent, depends, as we know, very largely upon the personal skill and good judgment of the physician who makes use of it. This method of regarding the subject will help to explain why certain conditions, such as neuralgia, may be treated successfully either by galvanism, static electricity or by the Roentgen ray; these apparently different forms of electricity being skillfully en

Taking a broad view of the subject, we obse ve that electricity is employed in therapeutics to a complish certain definite ends. These objects may in some cases be attained by several different methods or forms of application. It is also true that others ap
parently, so far as we know, can only be accompparently, so technique. In fact, particular means are often employed to obtain definite results, because at present they appear to be the best which

With regard to the modus medendi, or the physio logical action of the agent, we may observe that electricity may be used to produce the following effects:

1. To produce local necrosis, or an eschar. Limite

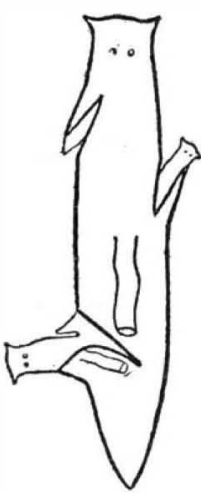
Fig. 8. - Planaria with Heads Sprouting in Various Parto
of the Body.

application may not go so far as to cause tissue or cel destruction, and may only produce local vascula changes, or, in other words, they may act as rubefacients or counter-irritants. Powerful currents, if passed
through the body, will, on the contrary, abruptly through the body, will, on the contrary, abrupte
terminate and abolish all physiological processes.

2. To disturb the electrical relations of the elements of nerves and muscles. This is shown by muscular contractions, produced when a nerve trunk and a voluntary muscle are brought within the infiuence of a current of appropriate strength. It is to be obditional strength to the nerve or muscle, but simply calls into action energy which is already there. However, by its power to call into play the latent energy of the muscle, it causes movements of the muscle which in turn leads secondarily to increased blood supply and improvement in nutrition. Illustrations of this are very common, as in treating muscular paralysis.

3. To modify metabolism. Its effects in this direction are well illustrated by the Roentgen apparatus.
Exposure to the X-rays causes local nutritive changes Exposure to the X-rays causes local nutritive changes
in the skin, the linugo hairs fall out from the operin the skin, the linugo hairs fall out from the oper-
ator's hands, the skin becomes glossy and thin from the atrophy of the glands, chronic ulceration may occur, which in turn may be followed by malignan disease. It has been repeatedly observed that un. guarded exposure of the body to the X-rays causes degenerative and atrophic changes in the deeper parts,
especially in the fundus of the eye. In therapeutics especially in the fundus of the eye. In therapeutics
this inhibitory and atrophic action may be skillfully this inhibitory and atrophic action may be skillfully
directed against cancerous or other new growths. directed against cancerous or other new growths.
The latter, having less power of resistance than norThe latter, having less power of resistance than normal tissue are made to undergo retrograde change and
to wither away. This is especially noticeable in to wither away. This is especially noticeable in
epithelioma of the skin, and also in accessible organs. epithelioma of the skin, and also in accessible organs.
4. To act as a temporary stimulant to nutritive pro4. To act as a temporary stimulant to nutritive pro-
cesses, and especially to the nervous system and the circulatory apparatus. This is illustrated by the good effects upon nutrition produced by the static current
and electric bath, in anæmia, neurasthenia, atonic dyspepsia, chronic rheumatism, and incipient tubercu-

5. To accomplish certain local effects by stimulating 5. To accomplish certain local efsects by stimulating
physiological functions. This is shown in the use of physiological functions. This is shown in the use of
electricity to increase the flow of milk from the mam. mary gland. The systematic application to the scalp causes improved nourishment of hair follicles, and not only prevents baldness, but also a

6. To destroy parasites upon the surface of the body. Many infectious diseases of the skin causer by vegetable micro-organisms are promptly cured by the X-rays.

7. To produce electrolysis. By means of needles introduced into the skin and the passage of a suitable alvanic current, decomposition of fluids and solids occurs, and as a result there may be absorption of
new growth. This is utilized in treating keloid or

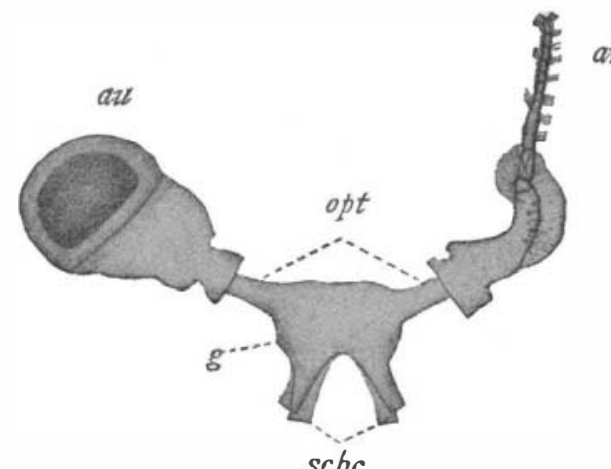

Fig. 9.-Formation of a Feeler Instead of an Eye in Palemon (a Decapod Crab).

a, brain ; opt, optic nerve: schc, optic com hypertrophied tissue of the nose or throat, and in the superfluous hair.

8. To produce intense light. The method, introduced by Finsen, which has been modified by the use of the electric source of illumination, has yielded of the electric source of illumination, has yielded
really remarkable results from its action upon lupus, really remarkable results from its action upon lupus,
and on some superficial malignant growths. The elec-
tric light bath has been vaunted as a great restorative tric light bath has been vaunted as a great restorative
agent, but its utility is doubtful. In its operation the entire body is exposed to several hundred incandescen lights. In studying its effects it is difficult to separ-
ate the effects of the heat of the bulbs (which acts ate the effects of the heat of the bulbs (which acts
like a Turkish bath) from the effects of the ligh itself. We know that light is very irritating to the nervous system, and that the intense sunlight of tropical regions makes these unfit for a permanent residence for white races of men. At all events, the electric light bath does not act like the electric bath, but simply as a light and heat bath.

9. To produce high degree of heat. I need not stop to speak of the uses of the galvanocautery in surgery. It is a complete substitute for the actual cautery, and is superior to it when used as the caustic loop in removing vascular growths on the tonsils; especially in cases of hemophilia.

10. To produce magnetic effects. The electric magnetic coil is used to extract iron fragments from the ance for detecting the location of a foreign body, such as a bullet embedded in the tissues.

The use of the X-ray in photography and in diag. within the province of the therapeutic applications of electricity.

I have now mentioned quite a number of useful applications of electricity in medicine, and I have by $\mathrm{no}$ means exhausted the list.

The second practical point I wish to make with rather desultory remarks, is this, and I regard it as a most important one:

Electricity, in most cases, is to be regarded as only an adjunct to other treatment. While giving the speate remedies to act upon the glands of excretion and 